\title{
Intoxicação por Indigofera suffruticosa (Leg. Papilionoideae) em bovinos ${ }^{1}$
}

\author{
Islaine de Souza Salvador ${ }^{2}$, Rosane M.T. Medeiros ${ }^{2}$, Clarice R.M. Pessoa ${ }^{2}$, \\ Antônio F.M. Dantas ${ }^{2}$, Gerôncio Sucupira Júnior ${ }^{3}$ e Franklin Riet-Correa ${ }^{2}$
}

\begin{abstract}
Salvador I.S., Medeiros R.M.T., Pessoa C.R.M., Dantas A.F.M., Riet-Correa F. \& Sucupira G.J. 2010. [Poisoning by Indigofera suffruticosa(Leg. Papilionoideae) in cattle.] Intoxicação por Indigofera suffruticosa (Leg. Papilionoideae) em bovinos. Pesquisa Veterinária Brasileira 30(11):953-957. Hospital Veterinário, Centro de Saúde e Tecnologia Rural, Universidade Federal de Campina Grande, Campus de Patos, 58700-970 Patos, PB, Brazil. E-mail: rmtmed@uol.com.br

Poisoning by Indigofera suffruticosa was diagnosed on a farm in the state of Paraíba, in the Brazilian semiarid region, in a herd of 25 cows and one bull. The herd was grazing for ten days in a paddock severely invaded by $I$. suffruticosa. Five days after the introduction into the paddock some cows showed red urine, and in ten days, when the herd was removed from the pastures, six cows had decreased milk production and hemoglobinuria. Five days after being withdrawn from the pastures, one cow showed aggressiveness and two days later was found death. At necropsy, the liver was yellowish with petechial hemorrhages on the surface and had increased lobular pattern. The kidneys were dark and with red spots up to $2 \mathrm{~mm}$ in diameter in the surface, which extended radially into the renal cortex. The urinary bladder was full of dark red urine. Upon histologic examination the kidneys had multifocal areas of ischemic tubular necrosis with hemoglobin deposition in the epithelial cells and hemoglobin casts in the tubules. The liver had diffuse paracentral and occasionally centrolobular coagulative necrosis. The other affected cows recovered spontaneously within 3-8 days after having been moved from the paddock. It is concluded that poisoning by $I$. suffruticosa, despite the spontaneous recovering of most cattle, can cause the death of some affected animals by acute hemolytic anemia.
\end{abstract}

INDEX TERMS: Poionous plants, Indigofera suffruticosa, Leguminosae Papilionoideae, plant poisoning, paracentral liver necrosis, hemolytic anemia, hemoglobinuria, cattle.

RESUMO.- Em uma propriedade do Município de Aparecida, no sertão da Paraíba, foi diagnosticada intoxicação por Indigofera suffruticosa em um rebanho de 25 vacas e um boi que foram colocados em um piquete que continha predominantemente $I$. suffruticosa onde permaneceram durante 10 dias. No quinto dia de pastejo o proprietário observou urina com coloração vermelho escura em uma vaca e ao final de dez dias de pastejo havia seis vacas

\footnotetext{
${ }^{1}$ Recebido em 2 de julho de 2010.

Aceito para publicação em 26 de julho de 2010.

${ }^{2}$ Hospital Veterinário, Centro de Saúde e Tecnologia Rural (CSTR), Universidade Federal de Campina Grande (UFCG), Campus de Patos, 58700-00 Patos, PB, Brasil. *Autor para correspondência: rmtmed@uol.com.br

${ }^{3}$ Curso de Medicina Veterinária, Centro de Saúde e Tecnologia Rural, Universidade Federal de Campina Grande, Campus de Patos, Patos, PB.
}

doentes apresentando hemoglobinúria e diminuição na produção leiteira. No quinto dia após serem retiradas do pasto uma vaca apresentou agressividade e no sétimo dia foi encontrada morta pela manhã. Na necropsia o fígado apresentava coloração amarelada com pontos avermeIhados e aumento do padrão lobular. A bexiga encontrava-se repleta com urina de cor vermelho escura. Os rins estavam escuros e com áreas hemorrágicas, de até $2 \mathrm{~mm}$, que se estendiam radialmente para dentro do córtex e parte da medula. Na histologia, os rins apresentavam áreas multifocais de necrose tubular isquêmica aguda com deposição de hemoglobina nas células epiteliais e cilindros de hemoglobina nos túbulos. No fígado havia necrose de coagulação difusa paracentral e ocasionalmente centrolobular. Os demais bovinos afetados se recuperaram espontaneamente 3-8 dias após serem retirados da pastagem. Conclui-se que a intoxicação por I. suffruticosa 
apesar de apresentar recuperação espontânea na maioria dos bovinos, mesmo se estes continuam ingerindo a planta, pode causar a morte de alguns animais por anemia aguda.

TERMOS DE INDEXAÇÃO: Plantas tóxicas, Indigofera suffruticosa, Leguminosae Papilionoideae, intoxicação por planta, necrose hepática paracentral, anemia hemolítica, hemoglobinúria, bovinos.

\section{INTRODUÇÃO}

Indigofera sufrutticosa (anil, anileira) (Fig.1) é uma planta originária das Antilhas e América Central, pouco exigente, que nasce em qualquer solo, inclusive em solos pedregosos. No Brasil, no passado, foi introduzida e cultivada em grande escala para a extração do corante anil natural, utilizado na indústria têxtil. Na década de 80 este corante foi substituído pelo anil produzido artificialmente (Alzugaray \& Alzugaray 1988). No Nordeste é considerada uma planta invasora, capaz de causar anemia hemolítica com hemoglobinúria e diminuição da produção, após poucos dias de consumo. O número de casos de intoxicação por esta planta em bovinos é aparentemente proporcional aos índices pluviométricos, surgindo em anos de grandes precipitações
(Barbosa Neto et al. 2001). De acordo com relatos de produtores, os animais apresentam os primeiros sinais poucos dias após serem colocados nos pastos onde predomina a planta. A morbidade oscila em torno de $50 \%$, sem distinção de sexo ou idade. A retirada dos animais dessas pastagens, no início do quadro clínico, possibilita rápida recuperação (Barbosa Neto et al. 2001).

Experimentalmente é tóxica para bovinos em doses de 10-40 g/kg/dia. O principal sinal clínico é a hemoglobinúria que aparece 24-144 horas após o início da ingestão. Os animais se recuperam espontaneamente em 24-144 horas, mesmo se continuam ingerindo a planta. As lesões macroscópicas são fígado de coloração azulada com evidenciação do padrão lobular e presença de urina marrom-escura na bexiga. Microscopicamente observa-se, no fígado, necrose coagulativa centrolobular e paracentral, e nos rins nefrose com presença de hemoglobina no espaço urinário, na luz de túbulos e no interior de células epiteliais nos rins (Barbosa Neto et al. 2001).

Apesar de numerosos relatos de produtores sobre a ocorrência da doença no semiárido Brasileiro, não há nenhum trabalho descrevendo surtos espontâneos da intoxicação. Além disso, não é mencionada a ocorrência de mortes causadas pela intoxicação espontânea. O objetivo deste traba-

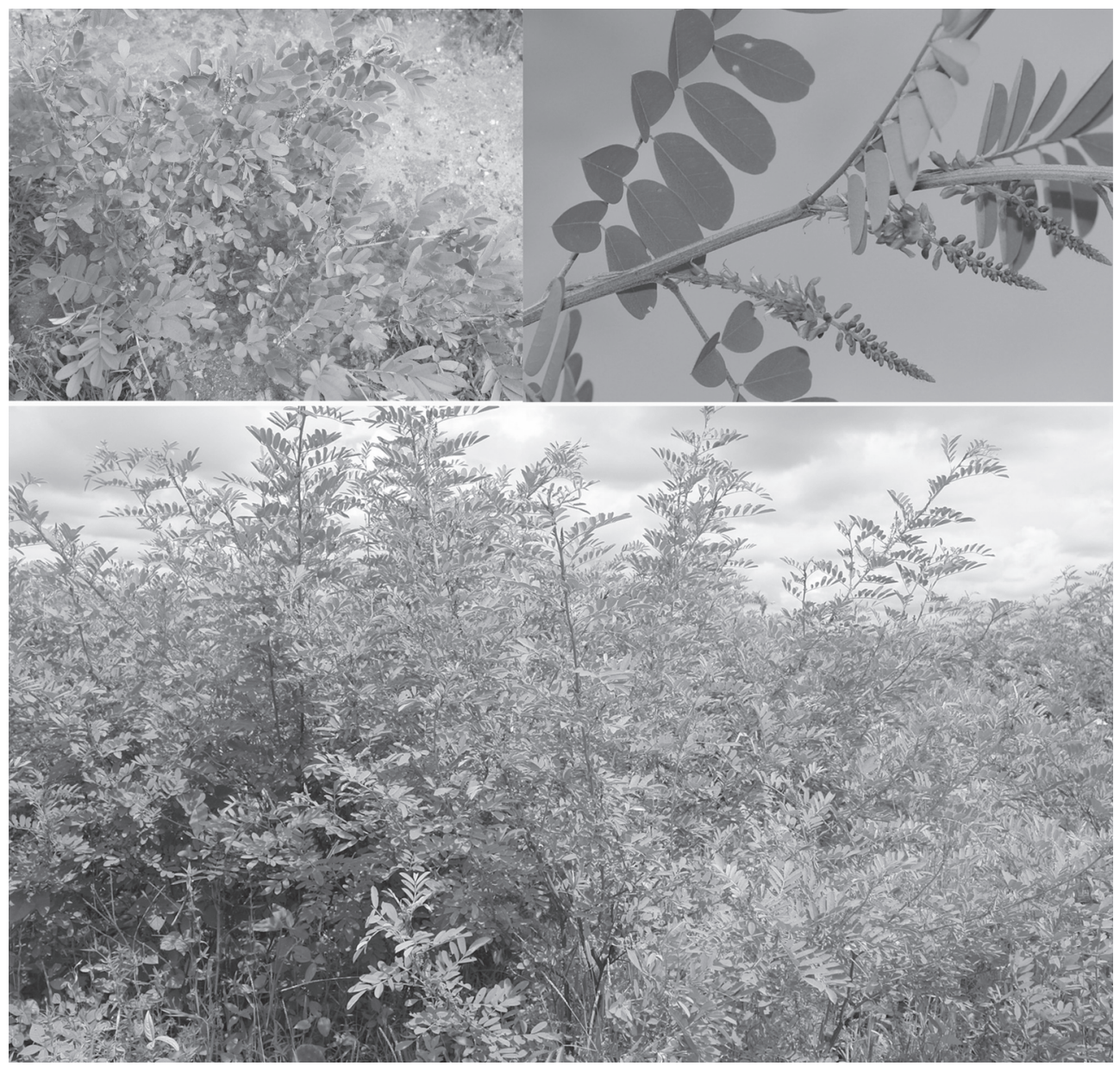

Fig.1. Indigofera suffruticosa. 
Iho é descrever um surto de espontâneo de intoxicação por I. sufrutticosa em bovinos, com morte por anemia hemolítica aguda, no semiárido Paraibano.

\section{MATERIAL E MÉTODOS}

No mês de julho de 2009 , foi realizada uma visita a uma propriedade rural, no município de Aparecida localizado no sertão do estado da Paraíba. Seis vacas de um rebanho de 26 animais de cruzas zebuínas, criado em regime extensivo, apresentaram hemoglobinúria e diminuição da produção leiteira. Um dos animais doentes, encontrado morto durante a visita à propriedade, foi submetido à necropsia, sendo coletados fragmentos de rim, fígado e encéfalo e fixados em formol tamponado a $10 \%$, incluídos em parafina, processados rotineiramente e corados por hematoxilina-eosina (HE). $\mathrm{O}$ histórico da doença e os dados clínicos e epidemiológicos foram obtidos com o proprietário.

\section{RESULTADOS}

Os animais tinham sido introduzidos em um piquete que continha, predominantemente, Indigofera suffruticosa (Leg. Papilionoideae), onde permaneceram durante 10 dias. No quinto dia de pastejo o proprietário observou urina com coloração vermelho escura (cor de vinho tinto) em uma vaca e no décimo dia de pastejo havia seis vacas apresentando hemoglobinúria e queda na produção leiteira. Em visita a propriedade foi observada, em alguns animais, urina de cor vermelha escura e, em outros, urina com pigmento azulado. O proprietário retirou os animais do pasto e observou o início da recuperação de algumas vacas após três dias. Após oito dias, todos os animais estavam completamente recuperados. Apenas uma vaca não apresentou melhora dos sinais clínicos, demonstrou agressividade no quinto dia após a retirada do pasto e no sétimo dia foi encontrada morta pela manhã, sendo realizada necropsia. $\mathrm{O}$ animal encontrava-se em bom estado corporal. $\mathrm{Na}$ necropsia a bexiga encontrava-se repleta com a urina de cor vermelho escura (Fig.2A). O fígado estava amarelado com hemorragias petequiais e aumento do padrão lobular (Fig.2B). A vesícula biliar estava aumentada de tamanho. $\mathrm{Na}$ superfície dos rins havia hemorragias multifocais de até $3 \mathrm{~mm}$ de diâmetro (Fig.2C) que ao corte se estendiam em forma de estrias até a medula (Fig.2D). Na histologia dos rins observou-se necrose tubular isquêmica aguda, caracterizada por necrose multifocal, preferentemente das células epiteliais dos túbulos próximas. Algumas células apresentavam grânulos de hemoglobina no citoplasma. Cilindros de hemoglobina eram observados nos túbulos, principalmente nas regiões onde macroscopicamente observavam-se estrias vermelhas que se estendiam desde 0 córtex até parte da medula. No fígado havia necrose paracentral de coagulação (Fig.3A-C), e algumas vezes
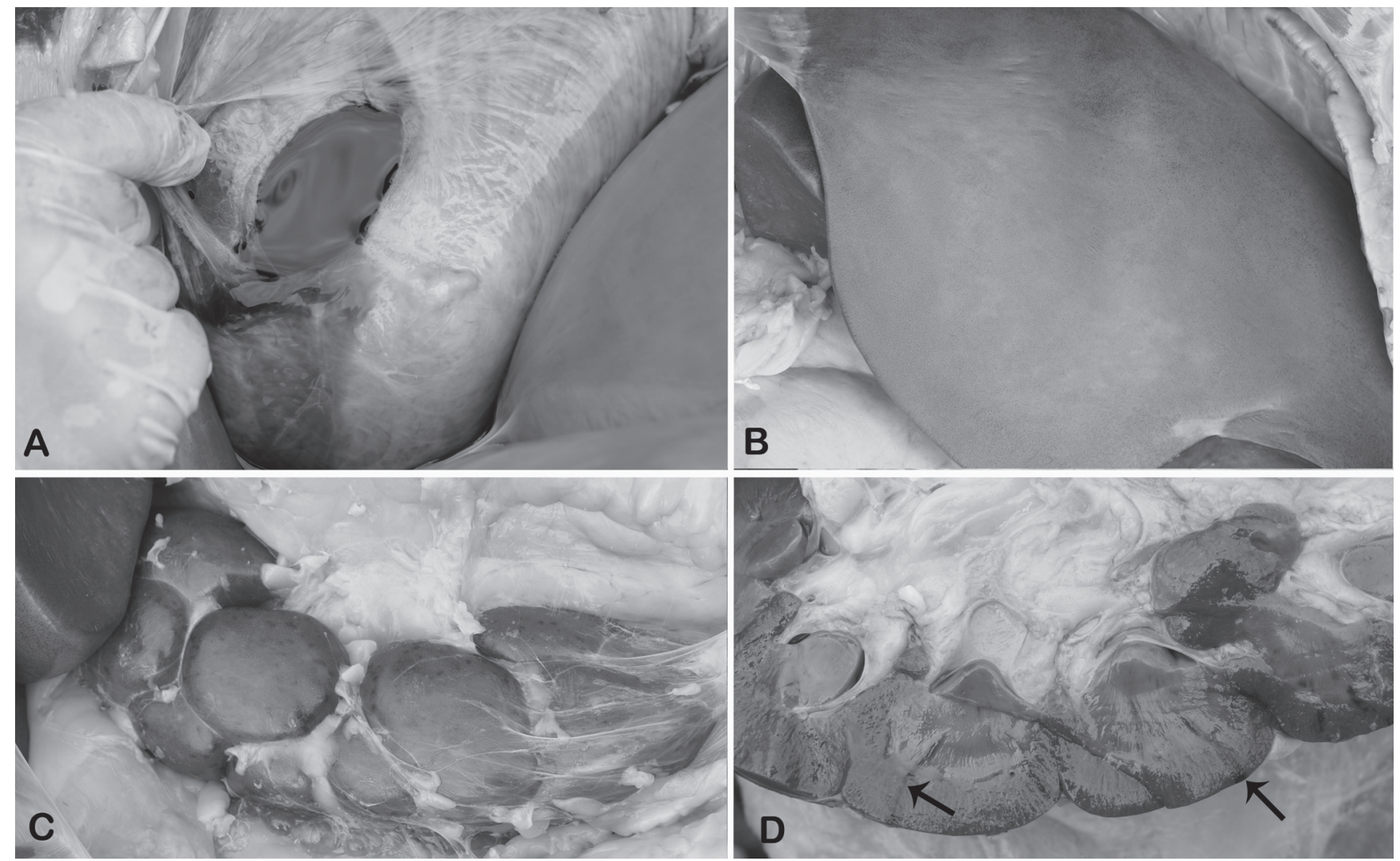

Fig.2. (A) Bexiga repleta de urina vermelha (hemoglobinúria), na intoxicação de bovino por Indigofera suffruticosa. (B) Fígado amarelado, com petéquias na superfície. (C) Rim apresentando hemorragias petéquias na superfície. (D) Superfície de corte do rim com áreas avermelhadas, de aspecto radiado que se estendem até o córtex (setas). 
centrolobular (Fig.3D). Ocasionalmente, observavam-se hemorragias margeando ou entremeando as áreas de necrose. Havia moderada presença de múltiplos vacúolos no citoplasma dos hepatócitos. No exame da urina coletada durante a necropsia foi observado hemoglobinúria, $\mathrm{pH}$ de 11 , presença de $0-5$ células epiteliais escamosas por campo, grande quantidade de bactérias (cocos e bacilos), 0-1 cristal de bilirrubina e 0-1 leucócito por campo.

\section{DISCUSSÃO}

O quadro clínico observado neste caso é semelhante ao descrito na intoxicação experimental por Indigofera suffruticosa em bovinos (Barbosa Neto et al. 2001); no entanto, neste surto foi registrada uma morte o que não aconteceu na intoxicação experimental, já que, experimentalmente, os animais se recuperam espontaneamente, mesmo continuando a ingerir a planta (Barbosa Neto et al. 2001). As lesões macroscópicas e histológicas são semeIhantes às descritas por Barbosa Neto et al. (2001) em um caso experimental que foi eutanasiado, no entanto não foi observada a coloração azulada do fígado mencionada por esses autores. No caso espontâneo a causa da morte pareceria ser anemia hemolítica aguda. A necrose preferentemente paracentral do fígado é característica de hipoxia causada por anemia (Starlker \& Hayes 2007) e as lesões renais são, aparentemente, devidas à hipoxia anóxica, também consequente da anemia (Newman et al. 2007). No encéfalo não foram observadas lesões de encefalopatia hepática e os sinais nervosos provavelmente ocorreram devido à encefalopatia anóxica.

A intoxicação foi diagnosticada pelos sinais clínicos e pela presença de grande quantidade da planta no pasto onde os animais se alimentavam e confirmado pelas lesões macro e microscópicas observadas no animal necropsiado. Como diagnóstico diferencial da intoxicação por I. suffruticosa deve-se incluir a intoxicação por outras plantas que cursam com sintomatologia semelhante. No Brasil, as intoxicações por plantas que causam hemólise incluem Brachiaria radicans (Gava 1993, Gava et al. 2010), Detaxis desertorum (Tokarnia et al. 1997) e Allium cepa (Borelli et al. 2007). A principal diferença entre essas intoxicações é a presença da planta. A intoxicação por Bra-
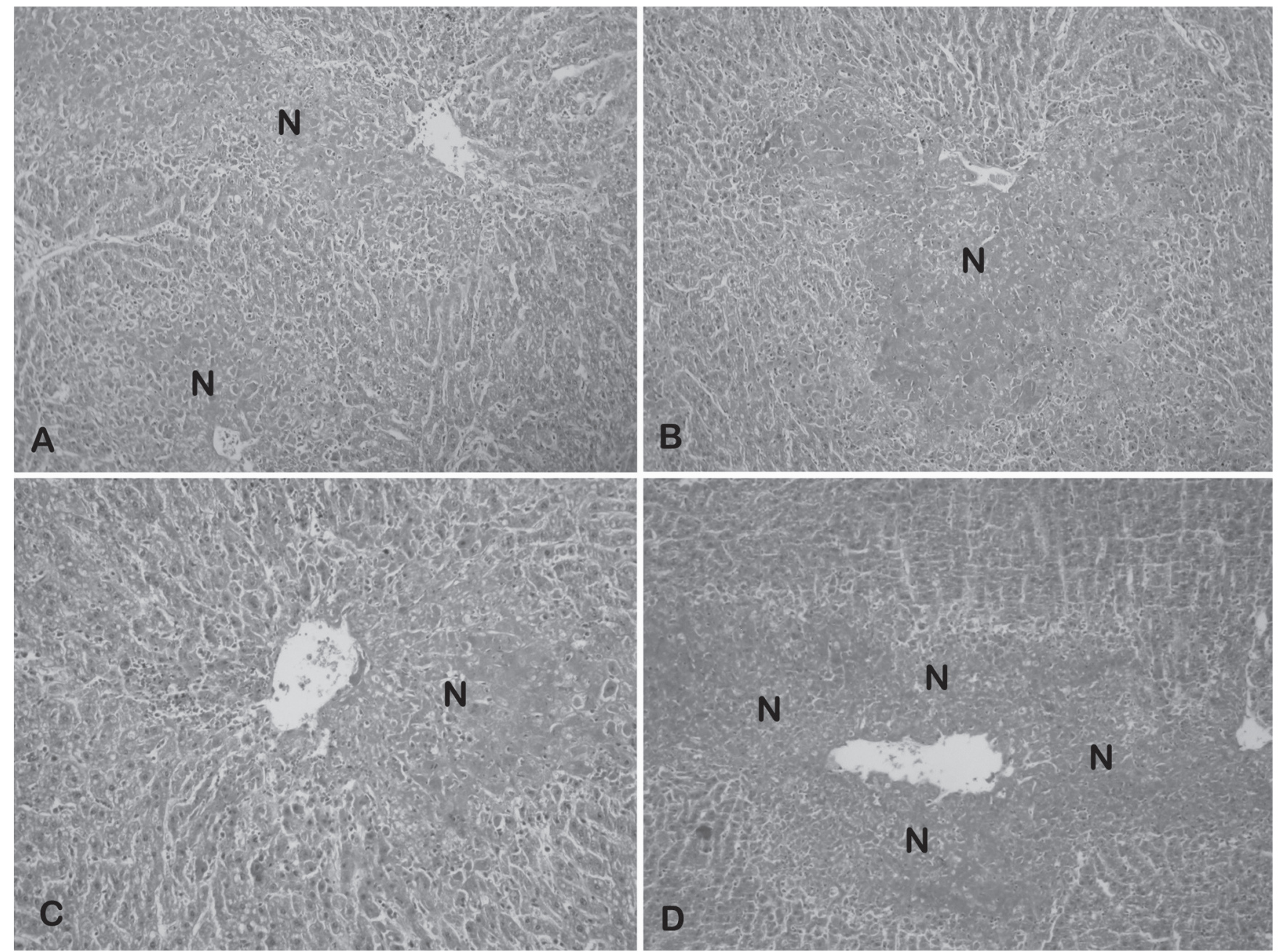

Fig.3. (A-C) Necrose hepática paracentral com diferente extensão e (D) necrose centrolobular ( $\mathrm{N}=$ necrose), na intoxicação por Indigofera suffruticosa em bovino. HE, obj.20x. 
chiaria radicans ocorre nas regiões sul e sudeste em pastagens formadas exclusivamente por $B$. radicans em solos férteis. A planta é encontrada no nordeste, geralmente em áreas baixas, inundáveis, mas surtos da intoxicação não têm sido descritos nesta região. A intoxicação por $D$. desertorum ocorre no Oeste do Estado da Bahia e, semeIhante ao observado na intoxicação por I. suffruticosa, a maioria dos animais recupera-se espontaneamente, mesmo continuando a ingerir a planta. A intoxicação por Alliun cepa (cebola) ocorre quando animais tem acesso a grandes quantidades de cebola, que são jogados fora por não terem sido comercializados (Borelli et al. 2007) ou quando tem acesso a restolhos de cultura de cebolas após a coleta. Surtos de intoxicação por cebola ocorrem esporadicamente no sertão Pernambucano (Bernardino 2010). Além da presença da planta a observação de pigmento azulado na urina é uma característica da intoxicação por $I$. suffruticosa que pode ser utilizada para o diagnóstico diferencial. Outras plantas que causam hemólise são Brassica spp., cuja intoxicação não tem sido diagnosticada no Brasil. O princípio ativo de Bassica spp. é o S-metilcisteina sulfóxido que no rúmen sofre o metabolismo de microorganismos sendo convertido em dimetil-dissulfeto e o de Allium cepa é $\mathrm{N}$-propil dissulfito, ambos são agentes oxidantes que afetam a membrana dos eritrócitos causando hemólise (Cheeke 1998).

A ocorrência de hemólise e hemoglobinúria pode fazer parte do quadro clínico de outras enfermidades como a babesiose (Almeida et al. 2006) e a intoxicação por cobre (Tokarnia et al. 2000), porém não havia carrapatos na propriedade e os animais não recebiam suplementação como concentrado, minerais ou cama de frango. Além disso, houve recuperação espontânea de muitos animais, fato que não ocorreria nessas duas enfermidades.

Como em geral bovinos intoxicados por I. suffruticosa recuperam-se espontaneamente a única medida recomendada é a retirado dos animais das áreas invadidas pela planta, entretanto, neste surto, a morte de um animal sugere que devem ser tomadas medidas para evitar mortes, mediante o acompanhamento do grau de anemia e o trata- mento, mediante transfusão de sangue, dos animais com hematócrito de $12 \%$ ou menor.

Agradecimentos.- Este trabalho foi financiado pelo INCT para o Controle das Intoxicações por Plantas (Proc. CNPq no. 573534/2008-0).

\section{REFERÊNCIAS}

Almeida M.B., Tortorelli F.P., Riet-Correa B., Ferreira J.L.M., Soares M.P., Farias N.A., Riet-Correa F. \& Schild A.L. 2006. Tristeza parasitária bovina na região sul do Rio Grande do Sul: estudo retrospectivo de 1978 a 2005. Pesq. Vet. Bras. 26:237-242.

Alzugaray D. \& Alzugaray K. 1988. Enciclopédia de Plantas Brasileiras, Editora Três, São Paulo, p.54.

Barbosa Neto J.D., Oliveira C.M.C., Peixoto P.V., Barbosa I.B.P., Ávila S.C. \& Tokarnia C.H. 2001. Anemia hemolítica causada por Indigofera suffruticosa (Leg. Papilionoideae) em bovinos. Pesq. Vet. Bras. 21(1):18-22.

Bernardino J.N.N. 2010. Comunicação pessoal (Veterinário Autônomo, Tabira, Pernambuco).

Borelli V., Furlan F.H., Traverso S. \& Gava A. 2007. Intoxicação por cebola (Allium cepa) em búfalos (Bubalus bubalis). XIII Encontro Nacional de Pesquisa Veterinária (Enapave), Campo Grande, MS (CD-Rom).

Cheeke P.R. 1998. Natural Toxicants in Feeds, Forages, and Poisonous Plants. 2nd ed. Danville, Illinois, p.302-306.

Gava A.1993. Intoxicação por Brachiaria radicans, p.319-322. In: RietCorrea F., Méndez M.C. \& Schild A.L. (Eds), Intoxicações por Plantas e Micotoxicoses em Animais Domésticos. Editorial Hemisfério Sul do Brasil, Pelotas, RS.

Gava A., Deus M.R.S., Branco J.V., Mondadori A.J. \& Barth A. 2010. Intoxicação espontânea e experimental por Brachiaria radicans (tanner-grass) em bovinos. Pesq. Vet. Bras. 30(3):255259.

Newman S.J., Confer A.W. \& Panciera R.J. 2007. Urinary system, p.613-691. In: McGavin M.D. \& Zachary J.F. (Eds), Pathologic Basis of Veterinary Diseases, Mosby, St Louis.

Stalker M.J. \& Hayes M.A. 2007. Liver and biliary system, p.297-388. In: Jubb K.V.F., Kennedy P.C. \& Palmer N.C. (Eds), Pathology of Domestic Animals. Vol.2. $5^{\text {th }}$ ed. Academic Press, San Diego.

Tokarnia C.H., Chagas B.R., Chagas A.D. \& Silva H.K. 1997. Anemia hemolítica causada por Ditaxis desertorum (Euphobiaceae) em bovinos. Pesq. Vet. Bras. 17:112-116.

Tokarnia C.H., Döbereiner J., Peixoto P.V. \& Moraes S.S. 2000. Outbreak of copper poisoning in cattle fed poultry litter. Vet. Human Toxicol. 42(2):92-95. 